\title{
'THOMSON TIME'
}

\author{
Athol Chase
}

During March 1979 four Aboriginal men from Lockhart River, Queensland, visited the National Museum of Victoria. Their journey, sponsored by the Australian Institute of Aboriginal Studies, was the result of their request to examine artefacts and photographs collected by Donald $F$. Thomson in this area of eastern Cape York during his fieldwork from 1928 to 1933 . This material forms part of the extensive Donald Thomson Collection held at the museum.

Dr Thomson is well remembered by older Lockhart people. 'Thomson time', as it is known, refers to a critical period in the history of the Umpila and Kuuku Ya'u people who today are part of the Lockhart community. This period is recognized as the last time of bush living, when small remnant groups resisted pressure to move into the then newly formed Lockhart River mission, and chose instead to remain in their homelands along the coast. Thomson is therefore remembered today as having worked with the last of the 'bush people' - those whose knowledge and expertise was fully traditional and little affected by the contact process.

For some time Lockhart people have been aware that a collection of artefacts and photographs existed. Some of Thomson's writings with photographs of ceremonies had reached the settlement over the years, and visiting anthropologists have provided other evidence. Indeed, older people remember Thomson's interest in gathering artefacts. From the time of my first visit in 1971 Lockhart men had asked where the collection was, who had access to it, and what it was used for.

Today, older men and women at Lockhart believe their distinctive culture is in a precarious situation, and feel real concern about the loss of traditional knowledge. Throughout their settlement history the various European administrations have been unsympathetic to their traditional life style and sought instead to implement assimilationist policies. In recent years the rapid disappearance of old people with pre-mission experience has meant that expert knowledge of such matters as ceremony and land tenure is becoming severely restricted Their concern has caused a number of requests to the Australian Institute of Aboriginal Studies for assistance in revisiting homelands and recording territorial affiliations. Several visits have been carried out. Lockhart men have been equally concerned about the performance of initiation ceremonies. Although these rituals have continued, there is concern about the decline of specialist knowledge needed for the manufacture and use of certain artefacts which are critical to correct performance.

The trip to Melbourne by Jimmy Doctor, Billy Clarmont, Mick Omeenyo and Roy Larsen was made with the expressed intention of examining Thomson Collection material related to these ceremonies. The visitors were particularly concerned to learn exactly what was in the collection, who was claiming ownership of it, how access to the material was controlled and what information on ritual could be retrieved from the objects made so long ago. Although many of these matters are still being thought over, the visitors expressed appreciation for the extraordinary care given to the collection and the formal safeguards placed upon the sacred material by the National Museum.

What they had not expected to find was the extensive collection of photographs relating to other dimensions of life besides ceremony. They were confronted with a detailed visual documentation of the life of their people fifty years ago. As an anthropologist visiting the museum with them I could share something of their emotion in seeing - perhaps for the first time - those people whose names are still remembered in the vivid oral history of this community. 
Today 'legitimate custodianship' is an issue for museums around the world, a complex issue being seriously discussed by curators and the communities whose past is recorded in museum collections. Curators everywhere are re-thinking the static approaches to display and preservation which prevailed in the past, and discovering that visiting 'experts' can add much to the documentation of material collected long ago.

This visit to the National Museum, in my view, suggests some of the benefits of co-operation between communities and curators. The Lockhart visitors clearly saw this museum collection as a reservoir of information about their culture, information thought to be lost but now available for use. This regained knowledge can be applied to current activities, in particular the formal ceremonies still important to this community. The stored information can also be used to enrich the present generation's perceptions of their own history and identity. One of the first reactions of this group was to request copies of certain photographs so that younger people can 'learn' the past and its people.

This community (and others) have found that the National Museum and the Australian Institute of Aboriginal Studies are sympathetic to the Aborigines' wish to preserve - and utilise - their heritage. Certainly this museum's response to Aboriginal concerns has demonstrated that curators and Aborigines have common interests, and that collections can be used in new ways. All of us who shared this rediscovery of the past felt that the visit was best described in a comment made afterwards by one of the Lockhart men: 'Too many things to think about now'.

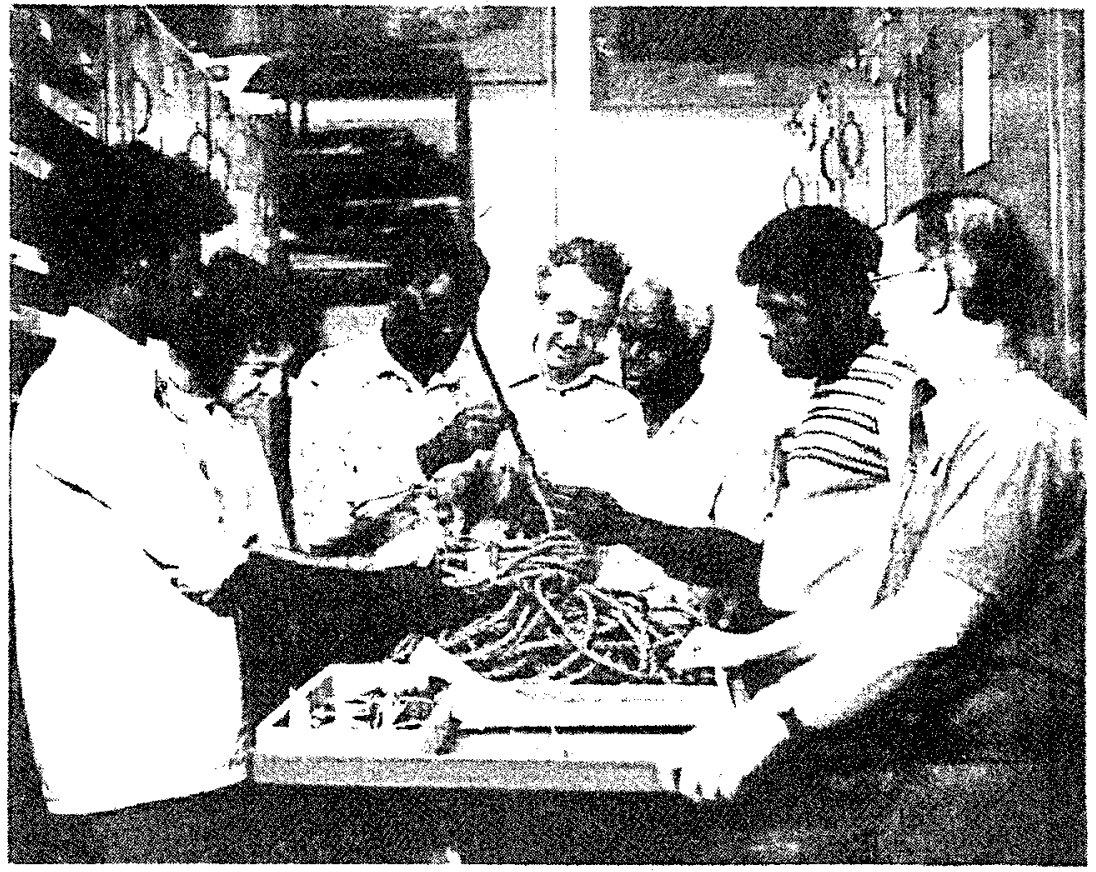

Lockhart River visitors examining the Donald F. Thomson Collection:

(Left to right): Roy Larsen, Peter Ucko, Jimmy Doctor, Athol Chase, Billy Clarmont, Mick Omeenyo, Alan West (Curator of Anthropology)

Photograph courtesy of National Museum of Victoria 